\title{
Implementasi Pendidikan Karakter Peduli Sosial di SMP Negeri 1 Karangtengah Demak
}

\section{Faiqotul Himmah, Tukidi, Ferani Mulianingsih ${ }^{\bowtie}$}

Social Science Education Department, Faculty of Social Science, Universitas Negeri Semarang, Indonesia

\begin{abstract}
Info Artikel
Sejarah Artikel:

Disubmit:

Direvisi:

Diterima:

\section{Keywords:}

character education; social care; social science education

Abstrak

Penguatan pendidikan karakter (PPK) diantaranya terdiri dari karakter peduli sosial sudah diterapkan di SMP Negeri 1 Karangtengah. Tujuan dari penelitian ini yaitu (1) Mendeskripsikan implementasi pendidikan karakter peduli sosial dalam pembelajaran IPS. (2) Mendeskripsikan bagaimana budaya sekolah dalam penanaman karakter peduli sosial. (3) Menjelaskan hambatanhambatan dalam implementasi pendidikan karakter peduli sosial di SMP Negeri 1 Karangtengah. Penelitian ini merupakan penelitian deskriptif kualitatif. Peneliti melakukan observasi, wawancara, dan dokumentasi. Analisis data menggunakan reduksi data, display data, dan penarikan kesimpulan. Teknik keabsahan data menggunakan triangulasi teknik dan triangulasi sumber. Hasil penelitian menunjukkan bahwa: (1) Pengimplementasian pendidikan karakter peduli sosial mulai dari persiapan pembelajaran, pelaksanaan pembelajaran dan evaluasi pembelajaran sudah berjalan dengan baik; (2). Budaya sekolah yang diterapkan di SMP Negeri 1 Karangtengah sudah mendukung penanaman karakter peduli sosial pada siswa. (3). Hambatan yang dialami dalam berupa hambatan dari guru IPS, perbedaan tingkat pemahaman siswa, serta pengaruh lingkungan luar.
\end{abstract}

\begin{abstract}
Character Education Strengthen (PPK), that consists of social care characther education, is applied at SMP 1 Karangtengah. The purposes of this study are: (1) Describing the implementation of social character education in Social Science learning. (2) Describing how the school culture in implementing social care character. (3) Describing the obstacles in the implementation of social care character education in SMP Negeri 1 Karangtengah. This is a qualitative descriptive study. Researchers conducted observations, interviews, and documentation. Analysis date uses reduction data, display data, and conclusions. The technique of data validity uses triangulation technique and triangulation source. The results showed that: (1) the implementation of educational character of social care starting from preparation of learning, the implementation of learning and evaluation of learning have been going well. (2) The school culture implemented in SMP Negeri 1 Karangtengah already supports the inculcation of social caring character in the students. (3) Obstacles experienced in the implementation of social care character education in the form of obstacles from IPS teachers, differences in the level of understanding of students, and the influence of the outside environment.
\end{abstract}

(C) 2019 Universitas Negeri Semarang

\footnotetext{
Alamat korespondensi:

Gedung C1 Lantai 1 FIS Unnes

Kampus Sekaran, Gunungpati, Semarang, 50229

E-mail: jurnalsosioliumpips@mail.unnes.ac.id
} 


\section{PENDAHULUAN}

Pendidikan karakter adalah suatu sistem penanaman nilai-nilai karakter kepada warga sekolah yang meliputi komponen pengetahuan, kesadaran atau kemauan, dan tindakan untuk melaksanakan nilai-nilai tersebut, baik terhadap Tuhan Yang Maha Esa (YME), diri sendiri, sesama, lingkungan, maupun kebangsaan sehingga menjadi manusia insan kamil (Narwanti, 2011: 14).

Materi pelajaran Ilmu Pengetahuan Sosial (IPS) berkenaan dengan fenomena dinamika sosial, budaya dan ekonomi yang menjadi bagian integral dalam kehidupan masyarakat dari waktu ke waktu dan dari tempat ke tempat, baik dalam skala kelompok masyarakat, lokal, nasional, regional dan global (Yusron, 2015:42). Ilmu Pengetahuan Sosial (IPS) berhubungan dengan hubungan manusia.

Data yang dirilis komisi perlindugan anak Indonesia (KPAI) berdasarkan survei international center for research on women (ICRW) sebanyak 84 persen anak di Indonesia mengalami kekerasan di sekolah. Angka kasus kekerasan di sekolah Indonesia lebih tinggi dari Vietnam 79\%, Nepal 79\%, Kamboja 73\%, dan Pakistan 43\%. (www.kpai.go.id 22 februari 2017). Maraknya kasus kekerasan pada anak akhirakhir ini disebabkan karena menurunnya rasa sosial diantara warga. Masyarakat khususnya di kota-kota besar cenderung cuek dan enggan bersosialisasi. Karena rasa antisosial itulah, maka kekerasan pada anak kerap terjadi. Degradasi moral khusunya pelajar sebagai generasi penerus bangsa diperlukan adanya perbaikan moral melalui penanaman pendidikan karakter peduli sosial agar karakter mulia dapat terwujud. Perilaku ini juga terjadi di kalangan siswa SMP Negeri.

Permasalahan sosial dikalangan peserta didik merupakan permasalahan yang perlu diatasi oleh seluruh kalangan, termasuk didalamnya institusi pendidikan yaitu sekolah (Ginanjar, 2017: 119). SMP menjadi lembaga yang melaksanakan pendidikan karakter. Salah satu nilai yang harus diterapkan yaitu nilai kepedulian sosial. Karakter peduli sosial adalah sikap dan tindakan yang selalu ingin memberi bantuan pada orang lain dan mayarakat yang membutuhkan (Daryanto, 2013: 71). Nilai-nilai pendidikan karakter peduli sosial termasuk dalam peraturan Presiden Republik Indonesia nomor 87 Tahun 2017 pasal 3 yang berisi Penguatan pendidikan karakter dilaksanakan dengan menerapkan nilai-nilai pancasila dalam pendidikan karakter terutama meliputi nilai-nilai religius, jujur, toleran, disiplin, bekerja keras, kreatif, mandiri, demokratis, rasa ingin tahu, semangat kebangsaan, cinta tanah air, menghargai prestasi, komunikatif, cinta damai, gemar membaca, peduli lingkungan, peduli sosial, bertanggung jawab.

Peneliti mengambil lokasi penelitian di SMP Negeri 1 Karangtengah karena sekolah ini merupakan sekolah yang menerapkan karakter. Pada observasi yang telah dilaksanakan terlihat bahwa SMP Negeri 1 Karangtengah menerapkan kurikulum 2013. Pada Kurikulum ini menerapkan karakter pada peserta didik dan diimplementasikan melalui proses pembelajaran. Nilai-nilai karakter yang disisipkan dalam pembelajaran sesuai dengan Pancasila, UndangUndang Dasar 1945 yang kembangkan melalui berbagai peraturan peundang-undangan dan di breakdown melalui Visi dan Misi sekolah sehingga terdapat berbagai program pembelajaran yang mendukung penguatan pendidikan karakter (PPK). Peduli pada teman bisa dilihat dari apa yang dilakukan oleh siswa diantaranya menjenguk teman ketika sakit, membantu teman yang sedang mengalami kesusahan, atau menolong teman yang sedang terkena bencana alam. Penanaman karakter peduli sosial penting untuk diterapkan sehingga peneliti tertarik untuk mengetahui lebih lanjut implementasi pendidikan karakter peduli sosial di SMP Negeri 1 Karangtengah. Oleh karena itu, penulis mengadakan penelitian dengan judul "Implementasi pendidikan karakter peduli sosial di SMP Negeri 1 Karangtengah".

Rumusan masalah dalam penelitian ini adalah (1) Bagaimana implementasi nilai karakter peduli sosial dalam pembelajaran IPS? (2) Bagaimana budaya sekolah dalam mengimplementasikan pendidikan karakter 
peduli sosial? (3) Apa saja kendala yang dihadapi pada saat implementasi nilai karakter peduli sosial dalam pembelajaran IPS?

Berdasarkan rumusan masalah, maka tujuan dari penelitian ini adalah untuk mengetahui (1) Implementasi nilai karakter peduli sosial dalam pembelajaran IPS, (2) Budaya sekolah dalam mengimplementasikan karakter peduli sosial, (3) Kendala atau hambatan-hambatan yang dihadapi guru IPS ketika mengimplementasikan karakter peduli sosial dalam pembelajaran IPS.

\section{METODE}

Penelitian ini menggunakan pendekatan dan jenis penelitian kualitatif. Pendekatan kualitatif bertujuan untuk mendapatkan pemahaman yang sifatnya umum terhadap kenyataan sosial dari perspektif partisipan (Purnomo, 2010:6). Peneliti menggunakan pendekatan ini karena ingin memahami lebih dalam tentang pelaksanaan pendidikan karakter peduli sosial dalam pembelajaran IPS. Penelitian dilaksanakan di SMP Negeri 1 Karangtengah yang terletak di Jalan Sultan patah Buyaran, Katonsari Karangtengah Demak pada tahun pelajaran 2017/2018. Hal menarik yang terdapat dalam sekolah ini yaitu adanya pembiasaan

Subjek dalam penelitian ini adalah guru IPS, Kepala Sekolah, dan siswa kelas VIII SMP Negeri 1 Karangtengah. Sumber data penelitian ini diperoleh dari data informan, kenyataan lapangan dan dokumen-dokumen. Teknik pengumpulan data menggunakan observasi tidak terstruktur, wawancara tidak terstruktur dan dokumentasi. Analisis data menggunakan analisis Miles dan Huberman. Uji keabsahan data penelitian ini dengan cara triangulasi yaitu pengecekan data dari berbagai sumber dan waktu.

Fokus penelitian ini adalah Implementasi pendidikan karakter peduli sosial dalam pembelajaran IPS. Penelitian ini juga meliputi budaya sekolah dalam mengimplementasikan pendidikan karakter peduli sosial di SMP Negeri 1 Karangtengah. selain kedua fokus penelitian tersebut, penelitian ini juga mengkaji hambatan dalam implementasi pendidikan karakter peduli sosial dalam pembelajaran IPSdi SMP Negeri 1 Karangtengah.

Sumber data penelitian terdiri dari informan utama dan informan pendukung. Informan utama penelitian ini merupakan guru IPS dan peserta didik SMP Negeri 1 Karangtengah yang memenuhi data dalam penelitian. Guru IPS yang dijadikan sebagai informan bernama Ibu Sofiyatun, S.Pd., hal ini karena guru IPS sebagai pelaksana kegiatan pembelajaran IPS di kelas lebih memahami bagaimana mengimplementasikan karakter peduli sosial dalam proses pembelajaran IPS. Sementara informan pendukung yang akan memberikan informasi-informasi tambahan data penelitian adalah Kepala Sekolah dan Waka Kurikulum. Sumber pendukung tersebut dipilih karena dipercaya dan mengetahui fokus penelitian secara mendalam, sehingga bisa membantu peneliti dengan memberikan keterangan yang ada di lapangan. Pengumpulan data dilakukan pada tanggal 31 Januari 2018 sampai 27 Maret 2018.

Penelitian ini menggunakan 3 sumber data, yakni (1) Informan, (2) Objek, dan (3) dokumen. Informan yang digunakan dalam penelitian ini adalah (a) Guru mata pelajaran IPS yaitu Ibu Sofiyatun, S.Pd. (b) Kepala Sekolah SMP Negeri 1 Karangtengah, yaitu Ibu Sri Titik Cahyaningsih, S.Pd., M.Pd. (c) Waka Kurikulum yaitu Ibu Sri Hari, S.Pd., (d) Perwakilan siswa-siswi SMP Negeri 1 Karangtengah yaitu Tina, Gigih, Alvin, Lutfi, dan Salsabila. Dokumen yang digunakan dalam penelitian berupa RPP, dokumentasi pembelajaran dan budaya sekolah. Dokumendokumen tersebut dipilih dan digunakan yang sesuai dalam penelitian.

\section{HASIL DAN PEMBAHASAN}

Penelitian ini dilaksanakan di SMP Negeri 1 Karangtengah yang terletak di Jl. Sultan Patah Buyaran, Desa Karangtowo, Kecamatan Karangtengah, Kabupaten Demak. 
Implementasi Pendidikan Karakter Peduli Sosial dalam Pembelajaran IPS

Implementasi pendidikan karakter peduli sosial diklasifikasikan melalui tiga proses yaitu perencanaan, pelaksanaan, dan evaluasi atau penilaian proses pembelajaran IPS

\section{Perencanaan Pembelajaran}

Perencanaan pembelajaran IPS mencakup pembuatan rencana pelaksanaan pembelajaran (RPP). Penyusunan RPP dilaksanakan berdasarkan kurikulum 2013. Perencanaan pembelajaran merupakan suatu proses awal yang dilakukan oleh seorang guru. Proses implementasi pendidikan karakter peduli sosial dalam pembelajaran IPS saat persiapan dilaksanakan melalui penyusunan perangkat pembelajaran yang dipersiapkan berupa rencana pelaksanaaan pembelajaran (RPP). Berdasarkan hasil wawancara di guru IPS membuat RPP dengan mengembangkaan pendidikan karakter yang disesuaikan dengan panduan pembuatan RPP berkarakter dengan mengintegrasikan nilainilai karakter termasuk karakter peduli sosial. Hal ini sesuai dengan Mulyasa (2013:81) yang menyatakan bahwa penyusunan RPP berkarakter sebagai produk program pembelajaran jangka pendek, yang mencakup komponen program kegiatan belajar dan proses pelaksanaan program.

\section{Pelaksanaan Pembelajaran IPS}

Kegiatan pembelajaran dari tahapan kegiatan pendahuluan, inti, dan penutup, dipilih dan dilaksanakan agar peserta didik mempraktikkan nilai-nilai karakter yang ditargetkan (Rachman, 2017: 69). Proses implementasi pendidikan karakter peduli sosial dalam pembelajaran IPS selanjutnya dapat dilihat dari pelaksanaan pembelajaran. Setelah guru IPS mempersiapkan pembelajaran yang meliputi penyusunan pembelajaran dan analisis terhadap karakteristik kelas kemudian guru IPS melaksanakan penanaman nilai-nilai peduli sosial dalam pelaksanaan pembelajaran IPS. Terdapat beberapa model pembelajaran IPS yang berbasis karakter peduli sosial yang digunakan oleh guru IPS di SMP Negeri 1
Karangtengah. Model pembelajaran yang digunakan disesuaikan dengan kondisi siswa. Dalam pelaksanaan pembelajaran guru IPS menerapkan rencana pembelajaran yang sesuai dengan rencana pelaksanaan pembelajaran (RPP) yang telah disusun. Terdapat tiga pokok dalam pelaksanaan pembelajaran yaitu kegiatan pendahuluan, kegiatan inti dan penutup. Indikator nilai peduli sosial yang di implementasikan dalam pembelajaran diantaranya: 1) berbagai kegiatan sosial; 2) meminjamkan alat kepada teman yang tidak punya; 3) memelihara kebersihan, keindahan dan kelestarian alam; 4) bertindak santun; 5) toleran terhadap perbedaan; 6) mampu bekerjasama.

\section{Evaluasi Pembelajaran}

Evaluasi pembelajaran berdasarkan kurikulum 2013. Penilaian yang dilakukan oleh Ibu Sofiyatun menggunakan beberapa model penilaian. Model-model penilaian tersebut merupakan penerapan dari rencana yang ada di RPP. Penilaian pengetahuan dilakukan dengan memberikan soal pilihan ganda dan uraian secara tertulis kepada siswa setelah materi selesai dilakukan. Sedangkan untuk penilaian keterampilan dilakukan melalui penugasan keterampilan melalui penugasan pembuatan makalah secara kelompok. Penilaian sikap akan menjadi pendukung penanaman sikap peduli sosial. Aspek sikap guru menilai dengan selalu membawa lembar penilaian siswa dan mencatat kejadian siswa. Penilaian sikap ini dilihat pada saat proses diskusi dalam pembelajaran IPS Terutama sikap sosial karena IPS erat sekali hubungannya dengan sikap sosial atau kepedulian sosial siswa. Sofiyatun menyatakan bahwa terdapat perubahan sikap, misalnya ketika satu peserta didik memberikan penjelasan materi yang belum dipahami teman-temannya.

Pembelajaran IPS di SMP Negeri 1 Karangtengah Demak yang terdiri dari kegiatan perencanaan, kegiatan pelaksanaan, dan evaluasi guru IPS sudah berhasil menanamkan karakter peduli sosial salah satunya diterapkan pada materi penguatan ekonomi maritim dan agrikultur di Indonesia. Hal ini sesuai dengan 
cara mengintegrasikan nilai-nilai karakter yang terdapat dalam materi pelajaran yang terdapat di dalam Desain Induk Pendidikan Karakter yang diterbitkan oleh Kemendiknas (2010: 21). Rahman (2013) dalam penelitiannya menyatakan bahwa guru memberikan pendidikan nilai kepedulian sosial melalui penenaman nilai secara verbal dan non verbal. Penanaman secara verbal dapat melalui pemberian motivasi, nasihat, cerita, teguran, hukuman, dan pujian

Budaya Sekolah dalam mengimplementasikan Pendidikan Karakter Peduli Sosial di SMP Negeri 1 Karangtengah Demak

Budaya sekolah
dalam mengimplementasikan pendidikan karakter peduli trcermin dari kegiatan rutin, kegiatan spontan, dan keteladanan. Kegiatan rutin merupakan kegiatan yang dilaksanakan secara konsisten dan terus menerus. Berdasarkan wawancara yang dilakukan kepada Kepala Sekolah, program rutin sekolah terdiri dari kegiatan harian dan mingguan. Kegiatan rutin harian yang dilakukan yaitu pembiasaan $3 \mathrm{~S}$ (Senyum, salam, dan sapa) dimana anak-anak akan melakukan ketika berada digerbang sekolah pada pagi hari saat masuk sekolah, dan saling menyapa dan mengucapkan salam kepada teman dan guru maupun karyawan ketika bertemu.

Kegitan spontan yang dilakukan yaitu ketika terdapat musibah yang menimpa teman maka akan ada siswa yang berkeliling untuk mendapatkan sumbangan dan antusias dari siswa sangat tinggi. Selain itu guru juga menanamkan pendidikan karakter peduli sosial dengan memberikan contoh nyata kepada siswa yaitu menegur siswa yang bersikap acuh tak acuh dan tidak peduli dengan temannya. Guru memberikan teguran pada siswa yang ramai sendiri dan tidak menghargai teman yang menyatakan pendapatnya di kelas.

Guru memberikan teladan secara langsung yang selanjutnya akan dicontoh oleh siswa. Guru memberikan teguran langsung, memberi contoh bagaimana cara bersikap yang baik, ikut menyisihkan sebagian uangnnya ketika ada infaq dan guru juga membantu kesusahan yang dialami oleh siswa misalkan ada seorang siswa kelas VIII yang kehilangan buku paket seorang guru akan langsung ikut membantu mencari bersama siswa lain. Selain itu pendidikan karakter peduli juga tercermin ketika pada saat pelajaran berlangsung atau upacara bendera hari senin terdapat siswa yang sakit maka guru akan mengantarkan ke UKS agar mendapatkan perawatan.

Berdasarkan pembahasan, SMP Negeri 1 Karangtengah telah menjalankan indikator nilai peduli sosial dengan baik. Sehingga dapat dikatakan bahwa sekolah berhasil mengintegrasikan nilai karakter peduli sosial dalam budaya sekolah. Pelaksanaan pendidikan karakter melalui budaya sekolah yang berjalan dengan baik akan mempermudah pendidik dalam membentuk karakter peduli sosial dalam diri siswa. Hal ini sesuai dengan pendapat Lickona (2012: 271) yang menyatakan bahwa sekolah itu sendiri harus mewujudkan karakter yang baik. Pendidikan karakter adalah tentang menjadikan sekolah berkarakter.

\section{Hambatan dalam Implementasi Pendidikan Karakter Peduli Sosial pada Pembelajaran IPS}

Beberapa hambatan dalam implementasi pendidikan karakter peduli sosial diantaranya guru masih kesulitan mengidentifikasi karakteristik belajar setiap peserta didik di kelasnya. Secara sosial guru masih belum secara penuh mengikuti semua kegiatan sosial yang ada di sekolahnya. Selain itu, Pada pelaksanaan pembelajaran IPS terdapat beberapa siswa yang tidak tertarik dengan pembelajaran IPS. Dalam penyusunan jam pelajaran, IPS terkadang ditempatkan pada jam terakhir yang biasanya konsentrasi siswa mulai berkurang. Masih belum efektifnya penilaian sikap yang dilaku kan. Hal ini menunjukkan bahwa guru harus ekstra dalam proses pembelajaran agar output yang dihasilkan bisa maksimal.

Pada proses implementasi pendidikan karakter peduli sosial kendala tersebut muncul dari lingkungan luar sekolah. Pada saat berada di lingkungan sekolah siswa masih bisa dikontrol langsung oleh sekolah, akan tetapi 
ketika sudah di lingkungan luar sekolah bukan menjadi tanggungjawab guru secara penuh.

Salah satu hambatannya sama seperti hasil penelitian yang pernah dilakukan oleh Fauzani (2018) dengan judul "Pelaksanaan pendidikan karakter kerjasama dalam pembelajaran PJOK di kelas tinggi bahwa hambatan yang dihadapi berdasarkan dari siswa, guru dan lingkungan masyarakat.

\section{SIMPULAN}

Hasil penelitian mengenai implementasi pendidikan karakter peduli sosial dalam pembelajaran IPS pada siswa SMP Negeri 1 Karangtengah yaitu Implementasi pendidikan karakter peduli sosial dalam pembelajaran IPS di SMP Negeri 1 Karangtengah, diantara karakter peduli sosial yang ditanamkan pada pembelajaran IPS yaitu: berbagi kegiatan sosial, meminjamkaan alat kepada teman yang tidak punya, memelihara kebersihan, keindahan dan kelestarian alam, bertindak santun, toleransi terhadap perbedaan, daan mampu bekerjasama. Penanaman karakter peduli sosial dalam pembelajaran IPS yang diajarkan oleh guru IPS dengan cara mengintegrasikan materi IPS dengan nilai-nilai peduli sosial. Dalam pembelajaran IPS metode yang sering digunakan oleh guru yaitu metode diskusi dan ceramah. Sedangkan bentuk evaluasi dilihat dari penilaian guru terhadap peserta didik serta perubahan tingkah laku yang dialami peserta didik.

Budaya sekolah yang ada di SMP Negeri 1 Karangtengah mendukung dan memberikan pengaruh terhadap penanaman karakter peduli sosial pada siswa. Budaya sekolah tersebut terdiri dari kegiatan rutin, kegiaatan spontan, dan keteladanan. Hal tersebut sudah relevan dengan penanaman karakter peduli sosial. Hambatan yang dialami dalam implementasi pendidikan karakter peduli sosial terdiri dari guru IPS, perbedaan tingkat pemahaman siswa, dan pengaruh lingkungan di luar.

\section{DAFTAR PUSTAKA}

Creswell. 2014. Research Design Pendekatan Kualitatif, Kuantitatif dan Mixed. Yogyakarta: Pustaka Pelajar.

Daryanto. 2013. Implementasi Pendidikan Karakter di Sekolah. Yogyakarta: Grava media.

Departemen Pendidikan Nasional. Undang-undang No.20 Tahun 2003. Sistem Pendidikan nasional.Jakarta: Depdiknas.

Fauzani, R.A. 2018. Pelaksanaan Pendidikan Karakter Kerjasama Dalam Pembelajaran PJOK Pada Siswa Kelas Tinggi Di SD Negeri Kraton Yogyakarta. Skripsi. Yogyakarta: Universitas Negeri Yogyakarta

Ginanjar, A. 2017. "Penguatan Peran IPS Dalam Meningkatkan Keterampilan Sosial Peserta Didik". Jurnal Harmony, 1 (1). Semarang: FIS UNNES

Kemendiknas. 2011. Panduan Pendidikan karakter di sekolah menengah pertama. Jakarta: Kementerian Pendidikan Nasional Direktorat jenderal pendidikan dasar direktorat pembinaan sekolah menengah pertama.

Kemendikbud. 2016. Silabus Mata Pelajaran IPS SMP/MTs. Jakarta: Kementerian Pendidikan dan Kebudayaan.

Mulyasa. 2013. Manajemen Pendidikan Karakter. Jakarta: Bumi Aksara.

Narwanti, Sri. 2011. Pendidikan Karakter Pengintegrasian 18 Nilai Pembentuk Karakter dalam Mata Pelajaran. Yogyakarta: Familia.

Purnomo, Arif. 2010. Metode Penelitian Pendidikan. Semarang : Universitas Negeri Semarang.

Rachman dan Lestari. 2017. Pendidikan dan Pembinaan Karakter Bangsa. Semarang. Fasrindo.

Rachman, M. 2013. Pengembangan Pendidikan Karakter Berwawasan Konservasi Nilai-Nilai Sosial. Jurnal Forum Ilmu Sosial, 40(1), 1-15.

Yusron, M. 2015. Penerapan Membaca Sintopikal untuk Menumbuhkan Karakter dan Meningkatkan Hasil Belajar Mata Pelajaran IPS Melalui Pembelajaran Model Reading Guide pada Siswa Kelas IX C SMP Negeri 16 Pekalongan Tahun Pelajaran 2012-2013. Jurnal Forum Ilmu Sosial, 42(1). 